
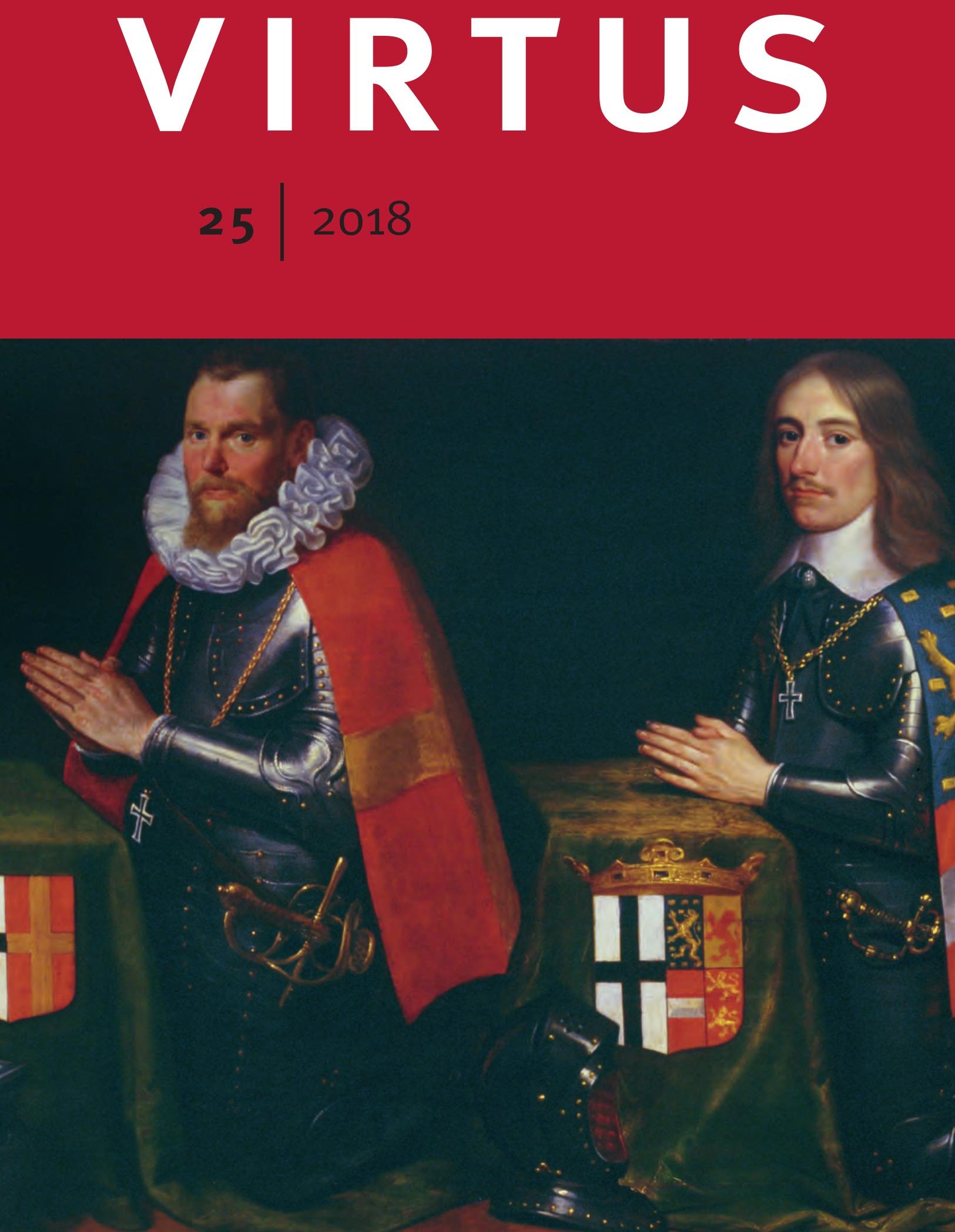


\section{Leon Wessels}

\section{Paradijsvogel in de Gelderse politiek}

Bert Koene, Een leven zonder toegeeflijkheid. Oranjeman Suideras, 1743-1811

(Hilversum: Uitgeverij Verloren, 2016, 176 p., ill., index)

De Grootste hoerendop dien ooit de zon bescheen

De grootste brabbelbaart, veragt van groot en kleen

(...)

Zulk een snoode deugniet woont noch in onze muuren

Dan werd gevloekt, gedoemd van al zijn nageburen

Hij lost en post en borgt en weet van geen betalen

Die schurk is Zuideras. De duivel mag hem haalen.

Dit versje verscheen in de winter van 1784 in de patriotse Zutphensche Courant. August Robbert van Heeckeren, beter bekend als Suideras, was een orangistische hardliner in de lokale politiek en dat maakte hem niet geliefd bij zijn tegenstanders. Bert Koene schreef een biografie over deze opmerkelijke man. Suideras was, in de woorden van Koene, 'voor menige tijdgenoot een bron van ergernis, voor andere juist een lichtend voorbeeld. Hij was het type van de kleurrijke figuur over wie iedereen een mening heeft.'

August Robbert werd in 1743 geboren als jongste kind van Frans Jan van Heeckeren en Transisalania C.J.A.A. van Rechteren. De Van Heeckerens waren een machtige adellijke clan in de Gelderse Achterhoek. Verschillende telgen hadden het geschopt tot landdrost van het Kwartier van Zutphen, het hoogste ambt in deze uithoek van de Republiek. Voor Robbert was dit ambt niet binnen handbereik. Zijn oudste broer Jacob Adolph was voorbestemd om in de voetsporen van zijn voorvaderen te treden. Niettemin verzekerde Robberts afkomst 
hem van een mooie startpositie. Nog voor hij zijn studie rechten in Harderwijk voltooide, kocht zijn vader voor hem de havezate Suideras bij Vierakker. Dit bezit verschafte hem toegang tot de Ridderschap van het Kwartier van Zutphen. Robbert ging voortaan door het leven als heer van Suideras of kortweg Suideras.

Suideras was zijn leven lang een zorg voor de familie. Zijn onverantwoordelijke gedrag bracht hem voortdurend in de problemen. Als twintiger had Suideras al tienduizenden guldens schuld. Hij leefde structureel boven zijn stand, ging lichtzinnige weddenschappen aan en omringde zich naar verluidt met vrienden die maar wat graag gebruikmaakten van zijn gulheid. Jacob Adolph, die na het overlijden van hun vader als familiehoofd gold, voelde zich verantwoordelijk voor de financiële situatie van zijn jonge broer. Suideras' groeiende reputatie als wanbetaler was immers een smet op het blazoen van de gehele familie. De pater familias deed zijn uiterste best om zijn broer uit het moeras van onbetaalde rekeningen te trekken, maar werd daarbij ernstig gehinderd door diens neiging om zijn werkelijke financiële toestand te verhullen met halve waarheden en hele leugens.

Suideras hoopte dat een huwelijk met een rijke burgerdochter zijn financiële situatie zou verbeteren. Hij had zijn pijlen gericht op Aleida Jacoba van Westrenen, telg uit een Utrechtse patriciërsfamilie. Aleida Jacoba was weliswaar ietwat beneden Suideras' stand, maar dat werd gecompenseerd door het vooruitzicht van een royale erfenis. Haar vader Jan André van Westrenen had de intenties van Suideras echter vroeg in de smiezen. Hij stond erop dat in de huwelijkse voorwaarden werd vastgelegd dat Suideras zijn schoonfamilie geen hulp kon vragen om eerder gemaakte schulden af te lossen. Bovendien stond hij zijn dochter niet toe haar erfdeel te verkopen. Suideras ging morrend akkoord. Het huwelijk was vanaf het prille begin ronduit ongelukkig. Suideras weigerde bij zijn vrouw in te trekken. Ondertussen werd het echtpaar geplaagd door de vele schuldeisers.

Nadat hij enige jaren raadsheer aan het Hof van Gelre was, werd Suideras in 1780 benoemd tot schepen van de stad Zutphen. Hij combineerde dit ambt met enkele lucratieve, arbeidsextensieve posten die niettemin onvoldoende waren om een einde te maken aan zijn geldproblemen. Suideras was zijn leven lang aanhanger van de Oranjes. In Zutphen leidde hij het verzet tegen de patriotse minderheid in het stadsbestuur, die werd aangevoerd door Robert Jasper van der Capellen tot den Marsch. In de roerige jaren die volgden werd Suideras meer en meer het mikpunt van spot voor zijn politieke tegenstanders. In de zomer van 1787 , toen de spanningen tussen patriotse burgers en prinsgezinde garnizoenssoldaten een hoogtepunt bereikten, speldde Suideras een oranje kokarde op zijn jas en paradeerde samen met de legercommandant door de straten van Zutphen. Deze stoutmoedige actie had effect. De straten van Zutphen kleurden oranje en de patriotten hielden zich voorlopig koest.

Suideras' optreden maakte indruk. Na de patriottentijd werd hij benoemd tot scholtus binnen en buiten Zutphen. Op het landdrostschap na was dit het hoogste ambt in het Zutphense kwartier. Toen in 1795 Franse troepen de patriotten in het zadel hielpen, had Suideras' reputatie echter een tegenovergesteld effect. Voor de burgers van Zutphen was hij volksvijand nummer één. Op last van de burgerij werd hij enkele dagen gevangengezet. Maar Suideras wist te ontkomen aan zijn politieke tegenstanders. Evenals andere orangisten vluchtte hij de Duitse grens over. In ballingschap beraamde de gewezen scholtus wilde en onrealistische plannen om het revolutionaire bewind ten val te brengen. In 1799 viel hij zelfs met een klein leger de Bataafse Republiek binnen. Deze onsuccesvolle invasie is de geschiedenis 


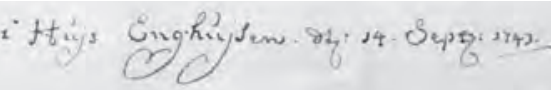

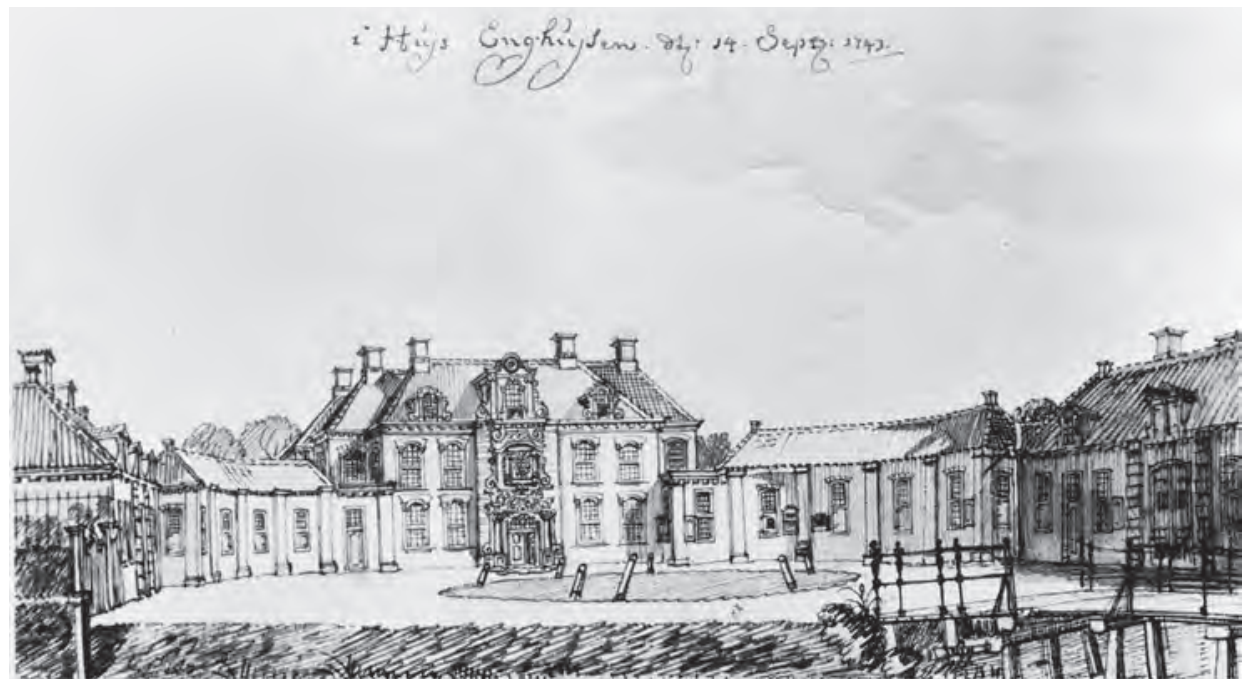

Huis Enghuizen, 1743, waar in datzelfde jaar August Robbert van Heeckeren tot Suideras (1743-1811) werd geboren (tekening, J. de Beyer; coll. Rijksdienst voor het Cultureel Erfgoed, objectnummer 33.078)

ingegaan als Gele Donderdag. Verslagen en teleurgesteld keerde Suideras in zijn laatste levensjaren terug naar de Republiek. Met dank aan oude vrienden die zich bereidwilliger hadden opgesteld ten opzichte van het nieuwe regime, kreeg hij een weinig beduidend baantje als vrederichter van Warnsveld. In die hoedanigheid stierf hij op 7 oktober 1811 in een Zutphense herberg.

Bert Koene, die eerder onder meer publiceerde over Gerard Brantsen en de familie Van Westerholt, zet in zijn levensschets van August Robbert van Heeckeren opnieuw een kleurrijk sujet in de schijnwerpers. 'Suideras was niet iemand van grijstinten', zo stelt de auteur droogjes in zijn conclusie. Het boek is ten dele een bijproduct van eerder onderzoek, waardoor Koene al bekend was geraakt met Suideras' stekelige karakter. Toch is Een leven zonder toegeeflijkheid een volwaardige, op zichzelf staande biografie. Koene is zeer goed bekend met de vele formele en informele facetten van het Gelderse bestuursapparaat. Het combineren van talrijke bronnen getuigt van zijn kwaliteiten als archiefonderzoeker. Helaas laat de schrijver zich af en toe verleiden om de technische aspecten van zijn archiefvorsing wat te uitvoerig uit de doeken te doen. Zo had de alinea die is gewijd aan de mogelijke datum waarop Suideras zich voor het eerst verloofde met Aleida Jacoba best in een voetnoot kunnen worden beschreven.

Maar een goede archiefonderzoeker hoeft nog geen goede historicus te zijn. Koene schrijft dat hij bewust terughoudend is geweest met commentaar op Suideras' gedrag. 'Ik wilde vooral de feiten laten spreken.' Die benadering is mijns inziens een misgreep. Het is niet de taak van de historicus om enkel feiten op te sommen, maar bovenal om die feiten te duiden. Pieter Geijl schreef het een slordige zeventig jaar geleden al, de geschiedenis is een 'discussie zonder eind'. De vraag hoe het verleden moet worden geïnterpreteerd is de kern- 
taak van de historicus. De antwoorden hierop zijn de spil van historische debatten binnen en buiten de academie. Aan het einde van het boek blijft de lezer dan ook zitten met verschillende onbeantwoorde vragen.

Een van de vragen die in de lucht blijft hangen is in hoeverre Suideras serieus werd genomen door de Oranjes. Tijdens zijn ballingschap correspondeerde Suideras met de erfprins, die hem zonder enige militaire ervaring aan het hoofd stelde van een klein invasieleger. Tegelijkertijd schreef de voormalige stadhouder aan zijn zoon dat Suideras na een geslaagde omwenteling 'geen positie van vertrouwen' zou moeten krijgen. Bovendien werd Suideras' geloofwaardigheid aangetast door de foutieve informatie die hij verspreidde en de listen die hij beraamde om aan geld te komen. Was Suideras één van de sleutelpersonen in het orangistische verzet tegen de Bataafse machtshebbers? Of was hij een schertsfiguur die vooral zelf geloofde in het belang van zijn daden?

Standsbesef is Koenes belangrijkste verklaring voor Suideras' handelen. Voor Suideras was de stand 'het fundament van het maatschappelijk leven'. Die verklaring lijkt in vele opzichten plausibel. Suideras was zich zeer bewust van de status van zijn familie. Hij weigerde een gesprek aan te gaan met een lokale timmerbaas omdat dat beneden zijn stand zou zijn. Mogelijk verklaart dit ook waarom Suideras van jongs af aan op veel te grote voet leefde. Hij mat zich een budget aan dat paste bij zijn status, maar niet bij zijn portemonnee. Iets gedurfder is Koenes vermoeden dat Suideras zich zo akelig gedroeg tegenover zijn echtgenote omdat zij uit een burgermilieu kwam.

Biografieën kun je ruwweg onderverdelen in twee typen. Het eerste type biografie beschrijft het leven van een zeer belangrijke persoon. Een nadere verantwoording is eigenlijk niet nodig. De persoon in kwestie (laten we zeggen Barack Obama) is dusdanig invloedrijk dat nadere informatie over diens leven gewenst is, in het bijzonder als die informatie nieuw licht schijnt op de totstandkoming van beslissingen. In het tweede type biografie speelt de hoofdpersoon feitelijk een ondergeschikte rol. De nadruk in een dergelijke biografie ligt op de tijdsgeest of het milieu waarin de hoofdpersoon verkeerde. Het individu dat centraal staat fungeert als gidspersoon om een groter verhaal te vertellen. Het tweede format wordt veelal (maar niet altijd) gebruikt voor boeken die geschreven worden voor een breder publiek. Alhoewel Suideras op zijn manier heeft bijgedragen aan de ontwikkelingen in zijn tijd, is de waarde van Een leven zonder toegeeflijkheid toch vooral de schets van een ruraal gebied in veranderende tijden en de rol die de lokale elite daarin speelde.

De rijkdom aan gegevens over Suideras' handel en wandel maken het boek interessant voor een divers lezerspubliek. Suideras' leven geeft een aardig inkijkje in de politieke cultuur in de tweede helft van de achttiende eeuw. Het nepotisme, het stadhouderlijke patronagesysteem en de opgewonden politieke gemoederen in deze jaren passeren allemaal de revue. Daarenboven kan de lezer wat opsteken over de adellijke familiemoraal en de strategische betekenis van het huwelijk. In dat opzicht is Een leven zonder toegeeflijkheid echter niet uniek. De laatste jaren zijn vele vergelijkbare boeken gepubliceerd. Op zichzelf is dat goed nieuws. De geïnteresseerde heeft inmiddels de keuze uit een keur aan biografieën over de vroegmoderne elite. Tegelijkertijd doet Koenes werk daardoor bij tijd en wijle aan als een verhaal dat je al eens eerder hebt gelezen. 
Adellijke echo's? De invloed van de adel op de ontwikkeling van buitenplaatsen langs de rivieren van het Amstelland en de Oude Rijn

Gerrit van Oosterom

Het Staatse ambassadegebouw in de zeventiende eeuw. Het logement van Hendrick van Reede van Renswoude in Madrid, 1656-1669

Maurits Ebben

Naar het Oosten. Geografische verschillen in het ledenbestand van de Ridderlijke Duitsche Orde, Balije van Utrecht, 1640-1840

Renger E. de Bruin

De Belgische orangistische adel I. De zuidelijke adel in het Verenigd Koninkrijk 79 der Nederlanden (1815-1830)

Els Witte

The Bentinck family archives. Highlights and suggestions for further research Menoucha Ruitenberg

Bildung und Erziehung. Zur Bedeutung zweier Schlüsselkategorien für Charlotte Sophie Gräfin Bentinck

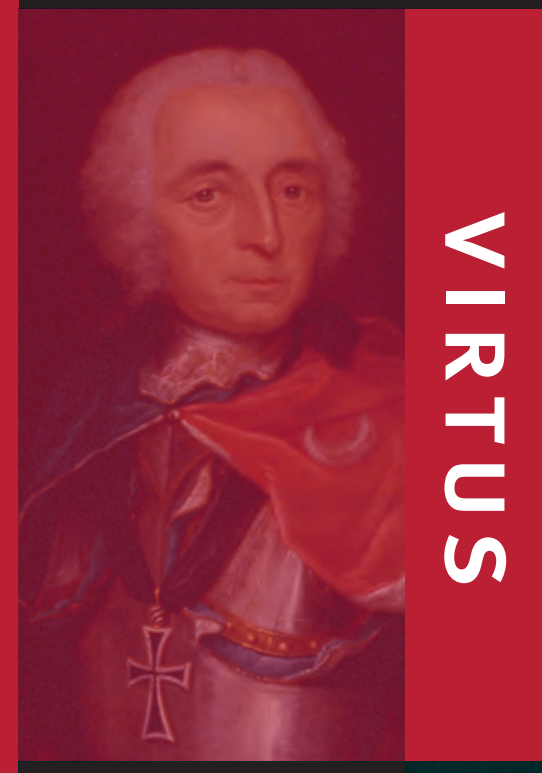

25 | 2018

Christina Randig

Charlotte Sophie, Joseph Eckhel and numismatics

Daniela Williams

Craignez honte. The Bentinck coats of arms and their use as an expression of the cross-border character of the family

\section{Olivier Mertens}

Fathers and Sons. A sketch of the noble life forms of the Bentincks in the 162 period of the Great Wars in Europe (1672-1748)

Yme Kuiper

Van wapenbord tot koningsboek. Herinnering, herstel en herbestemming in de heraldiek van het Gulden Vlies (1559-1795)

Steven Thiry 